5-19-2004

\title{
Evaluating The Contributions of Desolvation and Base-Stacking During Translesion DNA Synthesis
}

Xuemei Zhang

Case Western Reserve University

Irene Lee

Case Western Reserve University

Anthony J. Berdis

Cleveland State University, A.BERDIS@csuohio.edu

Follow this and additional works at: https://engagedscholarship.csuohio.edu/scichem_facpub

Part of the Biochemistry Commons, and the Chemistry Commons

How does access to this work benefit you? Let us know!

\section{Recommended Citation}

Zhang, Xuemei; Lee, Irene; and Berdis, Anthony J., "Evaluating The Contributions of Desolvation and BaseStacking During Translesion DNA Synthesis" (2004). Chemistry Faculty Publications. 190.

https://engagedscholarship.csuohio.edu/scichem_facpub/190

This Article is brought to you for free and open access by the Chemistry Department at EngagedScholarship@CSU. It has been accepted for inclusion in Chemistry Faculty Publications by an authorized administrator of EngagedScholarship@CSU. For more information, please contact library.es@csuohio.edu. 


\title{
Evaluating the contributions of desolvation and base-stacking during translesion DNA synthesis
}

\author{
Xuemei Zhang, Irene Lee and Anthony J. Berdis
}

DNA polymerases catalyze the insertion of a nucleoside triphosphate into the growing polymer chain using the template strand as a guide. Numerous factors such as hydrogen bonding interactions, base-stacking contributions, and desolvation play important roles in controlling the efficiency and fidelity of this process. We previously demonstrated that 5-nitro-indolyl-2'-deoxyriboside triphosphate, a non-natural nucleobase with enhanced basestacking properties, was more efficiently inserted opposite a non-templating DNA lesion compared to natural templating nucleobases (E. Z. Reineks and A. J. Berdis, Biochemistry, 2004, 43, 393-404). The catalytic enhancement was proposed to reflect increased base-stacking interactions of the non-natural nucleobase with the polymerase and DNA. However, the effects of desolvation could not be unambiguously refuted. To further address the contributions of base stacking and desolvation during translesion DNA replication, we synthesized indolyl-2'-deoxyriboside triphosphate, a nucleobase devoid of nitro groups, and measured its efficiency of enzymatic insertion into modified and unmodified DNA. Removal of the nitro group reduces the catalytic efficiency for insertion opposite an abasic site by 3600 -fold. This results from a large decrease in the rate of polymerization ( 450 -fold) coupled with a modest decrease in binding affinity ( $~ 8$-fold). Since both non-natural nucleobases show the same degree of hydrophobicity, we attribute this reduction to the loss of base-stacking contributions rather than desolvation capabilities. Indolyl-2'deoxyriboside triphosphate can also be inserted opposite natural nucleobases. Surprisingly, the catalytic efficiency for insertion is nearly identical to that measured for insertion opposite an abasic site. These data are discussed within the context of $\pi$-electron interactions of the incoming nucleobase with the polymerase:DNA complex. Despite this lack of insertion selectivity, the polymerase is unable to extend beyond the non-natural nucleobase. This result indicates that indolyl-2'-deoxyriboside triphosphate acts as an indiscriminate chain terminator of DNA synthesis that may have unique therapeutic applications.

\section{Introduction}

DNA polymerases are arguably one of the most complex catalysts found in nature. These enzymes catalyze the addition of mononucleotides into a growing polymer using a DNA template as a guide for directing each incorporation event. Although the chemistry of the transesterification reaction is well-defined, several questions still remain regarding the biophysical forces used by the polymerase to achieve the incredible degree of substrate fidelity during the reaction. A specific question is how the polymerase recruits an incoming deoxynucleoside triphosphate (dNTP) substrate from bulk solvent and then selectively places it opposite the proper complementary partner in the template strand. This is a daunting task since the template strand is heteropolymeric, and its changing nature places additional strains on the already high demand for substrate specificity. In most cases, polymerases paradoxically maintain a high degree of selectivity by inserting only one of four potential dNTPs opposite a template place while possessing an extraordinary degree of flexibility to recognize four distinct pairing partners. An additional complication is that the polymerase performs the repetitive task of nucleobase pairing and transesterification at a rate of nearly $1000 \mathrm{bp} \mathrm{s}^{-1}$. $^{2}$

The simplest model accounting for the high catalytic efficiency during DNA replication invokes direct hydrogenbonding interactions between the incoming and templating nucleobases (reviewed in $^{3}$ ). If the functional groups of the nucleobases properly align as acceptor-donor pairs, then the polvmerase rapidly catalvzes the transesterification reaction.
If the groups do not properly align, then either ground state binding is weakened ${ }^{4-6}$ or the rate of transesterification is reduced $^{7-9}$ such that misincorporation events should rarely occur. While elegantly simple, the validity of this model has been weakened since the measured misinsertion frequencies are lower than that predicted from the free energy differences $\left(\Delta \Delta G^{\circ}\right)$ between the corresponding matched and mismatched base pairs (reviewed in ${ }^{10}$ and ${ }^{11}$ ). Secondly, this model does not account for the desolvation of the incoming dNTP which is absolutely necessary for the formation of hydrogen bonds within the interior of the DNA helix (reviewed in ${ }^{12}$ and ${ }^{13}$.

A more advanced model is that invoking "steric fit" or "shape complementarity" as the predominant driving force. ${ }^{14-16}$ In general, the efficient insertion of isosteric analogs of natural nucleobases into DNA suggests that the geometrical alignment of the incoming nucleobase with the template base optimizes polymerization efficiency and fidelity. ${ }^{14}$ Indeed, several independent laboratories have demonstrated that various nonnatural, non-hydrogen-bonding nucleobases can be effectively opposite natural or modified bases. ${ }^{17-22}$ More relevant to this report is the demonstration that the large, aromatic non-natural nucleoside, pyrene-2'-deoxyriboside triphosphate (dPTP, Fig. 1A), is inserted opposite an abasic site $\sim 100$-fold more effectively compared to dAMP insertion. ${ }^{15}$ This result was initially interpreted as evidence for the steric fit model and was subsequently corroborated by modeling studies revealing that the overall shape and size of the pyrene:abasic mispair is nearly identical to that of natural adenine:thymine pair. ${ }^{15}$ 
<smiles>CCn1cnc2c(N)ncnc21</smiles>

5-NITP<smiles>Cn1ccc2cc([N+](=O)[O-])ccc21</smiles>

Ind-TP<smiles>CCCn1ccc2ccccc21</smiles>

dPTP<smiles>CCCc1ccc2ccc3cccc4ccc1c2c34</smiles>

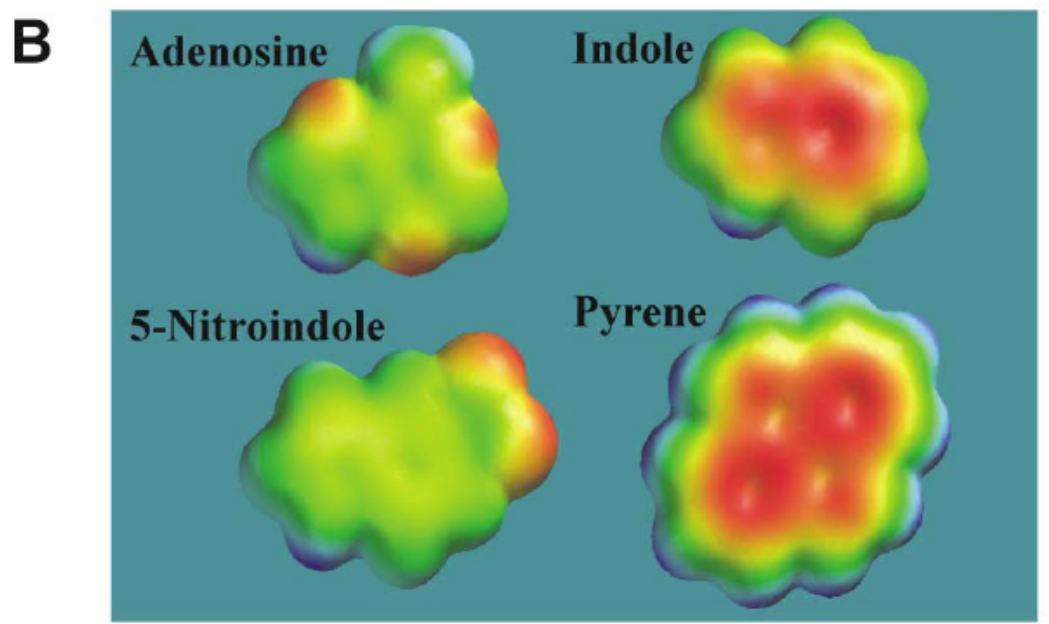

C

\section{5' - TCGCAGCCGTCCA \\ 3' - AGCGTCGGCAGGTXCCCAAA}

\section{$\mathbf{X}=\mathbf{A}, \mathbf{C}, \mathbf{G}, \mathbf{T}$ or abasic site}

Fig. 1 (A) Structures of 2'-deoxynucleoside triphosphates used or referred to in this study are dATP, 5-NITP, Ind-TP, and dPTP. For convenience, $\mathrm{dR}$ is used to represent the deoxyribose triphosphate portion of the nucleotides. (B) Electrostatic surface potentials for each nucleobase are provided for comparison and were generated using Spartan ' 04 software. Red indicates the highest electronegative regions, green is neutral, and blue indicates electropositive regions. The partial atomic charges were calculated using Hartree-Fock 3-21G $\left({ }^{*}\right)$ (displayed) or the AM1 model (data not shown). (C) Defined DNA substrates used for kinetic analysis. "X" in the template strand denotes any of the four natural nucleobases or the presence of a tetrahydrofuran moiety designed to mimic an abasic site. As noted, we have employed tetrahydrofuran as a mimic for a true abasic site since the tetrahydrofuran moiety is resistant to hydrolysis and thus more stable. In general, the presence or absence of the hydroxyl group has a minimal effect on the preference or kinetic parameters for dNMP insertion. ${ }^{15}$

However, it has been recently proposed that other physicochemical features of dPTP such as base-stacking capabilities could also account for its efficient insertion opposite this nontemplating lesion. ${ }^{23}$ In this regard, we provided experimental evidence for the importance of base-stacking by measuring the insertion of a series of modified nucleotides opposite an abasic site. ${ }^{24}$ Our studies demonstrated that 5-nitro-indolyl-2'deoxyriboside triphosphate (5-NITP, Fig. 1A) was inserted opposite an abasic site with approximately 1000 -fold greater efficiency compared to the preferred natural nucleotide, dATP. ${ }^{24}$ Remarkably, the $k_{\text {pol }}$ value of $126 \mathrm{~s}^{-1}$ and the $K_{\mathrm{d}}$ value of $18 \mu \mathrm{M}$ measured for the insertion of 5-NIMP opposite the lesion ${ }^{24}$ are nearly identical to those for the enzymatic formation of a natural Watson-Crick base pair. ${ }^{25,26}$ More impressive is the fact that 5-NITP is effectively inserted opposite the lesion despite its much smaller size and surface area compared to pyrene. The low correlation between size and catalytic efficiency prompted us to propose that the enhanced base-stacking capability of 5 -NITP ${ }^{24,27}$ plays a predominant role in catalysis during translesion DNA synthesis.

The lack of conventional hydrogen bonding groups on 5-nitroindole also contributes to its hydrophobic nature and enhanced desolvation capabilities. In fact, these properties could also account for the enhanced insertion rates opposite the lesion. To distinguish between base-stacking and desolvation, we synthesized indolyl-2'-deoxyriboside triphosphate (Ind-TP, Fig. 1A), a hydrophobic nucleobase devoid of extensive base-stacking capabilities, and measured its insertion into DNA. In this report, we provide kinetic evidence that removal of the nitro group significantly decreases the efficiency of insertion opposite an abasic site. This reduction occurs through a large decrease in the rate constant for polymerization coupled with smaller perturbations in nucleotide binding. More surprisingly, the non-natural nucleobase is inserted opposite 


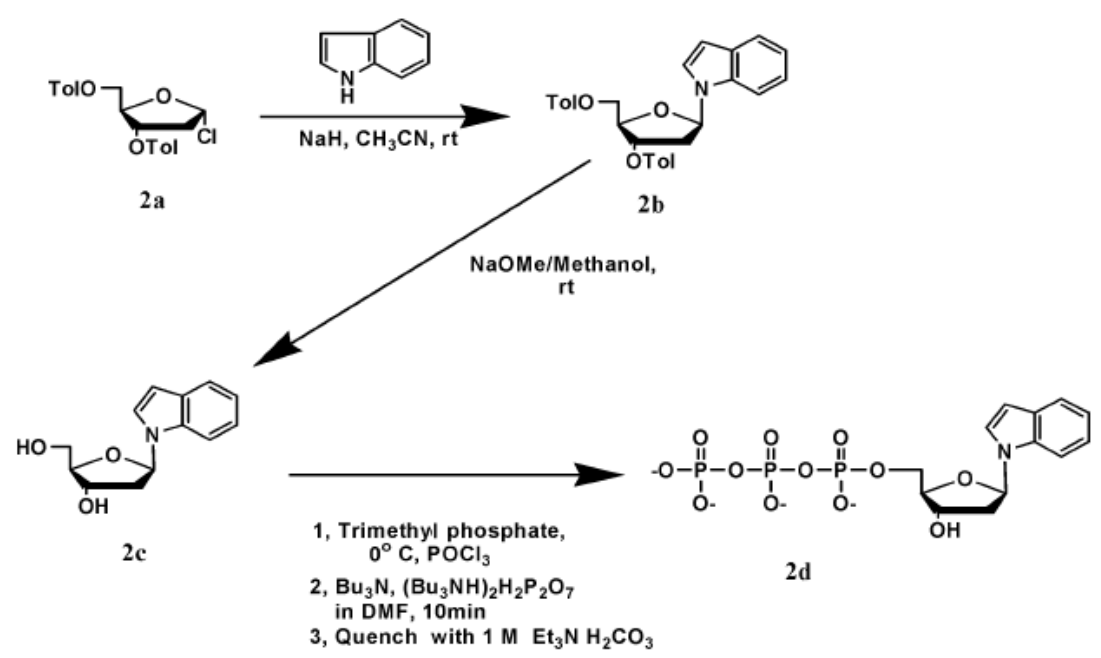

Fig. 2 Outline of synthesis of indolyl-2'-deoxyriboside triphosphate. See text for experimental details.

natural template nucleobases with equal catalytic efficiencies. The ability of the polymerase to easily form either purine: pyrimidine or purine:purine mispairs detracts from the importance of shape complementarity as the predominant driving force for catalytic efficiency. These results are interpreted with regards to reported structures of the DNA polymerase. $^{28-30}$ Finally, we demonstrate that the non-natural nucleobase displays unique chain termination capabilities since the polymerase cannot extend beyond it once inserted into DNA.

\section{Results and discussion}

Synthesis and chemical characterization of indolyl-2'deoxyriboside triphosphate

The indole nucleoside triphosphate reported in this study was synthesized as outlined in Fig. 2 using the protocol of Girgis $e t$ $\mathrm{al}^{31}$ to generate the nucleoside (2c), and the protocol of Smith et $a .^{32}$ to generate the triphosphate (2d). In brief, the sodium salt of indole, generated in situ by addition of sodium hydride in dry acetonitrile, was reacted with 1-chloro-2-deoxy-3,5-di- $O$ $p$-toluoyl- $\alpha$-D-erythro-pentofuranose (2a) at room temperature to yield $2 \mathbf{b}^{31,33} \mathbf{2 b}$ was further deprotected with sodium methoxide to yield the $\beta$-anomeric isomer (2c) as confirmed by ${ }^{1} \mathrm{H}-\mathrm{NMR}$ NOE difference spectroscopy (NOE's of H-2, H-7, $\mathrm{H}-4^{\prime}, \mathrm{H}-2^{\prime}{ }_{\alpha}$, and $\mathrm{H}-2^{\prime}{ }_{\beta}$ upon irradiation of $\left.\mathrm{H}-1^{\prime}\right)$. No $\alpha$-isomer was obtained.

The indole nucleoside (2c) was treated first with phosphorus oxychloride to form the monophosphate chloride, and then reacted with pyrophosphate to form the nucleoside 5 '-triphosphate as described. ${ }^{32}$ The overall yield of indole nucleoside triphosphate (2d) from the nucleoside $2 \mathrm{c}$ was $5 \%$. In addition to $\mathbf{2 d}$, two side products, $\mathbf{3 a}$ and $\mathbf{3 b}$ were recovered from the conversion of $\mathbf{2 c}$ to $\mathbf{2 d}$. The structures of $\mathbf{3 a}$ and $\mathbf{3 b}$ were determined by FAB mass spectrometry, ${ }^{1} \mathrm{H}$ as well as ${ }^{13} \mathrm{C}$ NMR spectroscopy. Both 3a and 3b have a molecular weight of 233 , clearly supporting the argument that they are isomers of the starting material 2c. Assignment of each respective isomer's structure was made according to the ${ }^{1} \mathrm{H}$ and ${ }^{13} \mathrm{C}$ chemical shifts values and the coupling constants of the anomeric protons which are summarized in Table 1. It has been established by Seela et $a .^{34}$ that pyranosides exhibit two different coupling constants for the anomeric protons: a larger coupling constant of $8-10 \mathrm{~Hz}$ for one, and a smaller coupling constant of $1-4 \mathrm{~Hz}$ for the other. The two coupling constants for the anomeric protons of the furanoside are closer to one another, and range between $5-9 \mathrm{~Hz}$ in magnitude. ${ }^{34}$ As shown in Table 1 , the coupling constants for the anomeric proton of the desired furanoside (2c) are 7.7 and $6.0 \mathrm{~Hz}$, respectively and agree well with published reports. ${ }^{34}$ As for the two side products $3 \mathbf{a}$ and $\mathbf{3 b}$, the coupling constants for each set of anomeric protons exhibit large differences $(11 \mathrm{~Hz}$ versus $1.6 \mathrm{~Hz}$ in $3 \mathrm{~b}$ and $10.1 \mathrm{~Hz}$ versus $1.2 \mathrm{~Hz}$ in 3a), indicating that both compounds are pyranosides. Since $\alpha$-pyranoside resonates at lower field in ${ }^{1} \mathrm{H}$ NMR spectroscopy,${ }^{34}$ we conclude that the signal observed at $5.86 \mathrm{ppm}$ for $3 \mathrm{a}$ corresponds to the $1^{\prime} \mathrm{H}$ in the $\alpha$-anomer. By the process of elimination, the signal observed at $5.63 \mathrm{ppm}$ for $\mathbf{3 b}$ is assigned to the $1^{\prime} \mathrm{H}$ in the $\beta$-anomer. The assignment of these two anomers is further supported by the ${ }^{13} \mathrm{C}$ chemical shifts of the respective $1^{\prime} \mathrm{C}$, in which $\alpha$-anomer resonates at a higher field than the $\beta$-anomer. ${ }^{35}$

To account for the formation of $\alpha$ - and $\beta$-pyranosides (3a and 3b) in the indole nucleoside triphosphate synthesis, we propose an acid-catalyzed furanoside-pyranoside isomerization step that competes with mono-phosphorylation of $\mathbf{2 c}$ ( Fig. 3). We speculate that hydrogen chloride was generated as a product when $\mathrm{POCl}_{3}$ reacted with the hydroxyl group in the nucleoside. As illustrated in Fig. 3, the resulting acidic environment could facilitate ring-opening. This hypothesis is supported by the 5 -fold increase in the yield of $2 \mathbf{d}$ when the proton sponge, 1,8-bis(dimethylamino)naphthalene, is included in the reaction. ${ }^{36}$ Using this method, we have likewise improved the yield for the synthesis of 5-nitro-indole nucleoside triphosphate from $12.5 \%$ to $50 \%$ (data not shown).

\section{Enzymatic insertion opposite an abasic site}

We measured the relative efficiency for Ind-MP, 5-NIMP, and dAMP insertion opposite an abasic site using a defined DNA substrate containing the lesion in the template strand (Fig. 1C). Time courses in primer elongation were generated using $10 \mathrm{nM}$

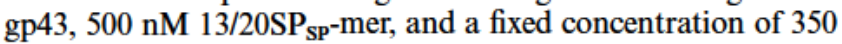
$\mu \mathrm{M}$ deoxynucleoside triphosphate that is at least 10 times the reported $K_{\mathrm{d}}$ values for dATP ${ }^{25,26}$ and 5-NITP, ${ }^{24}$ respectively. Gel electrophoresis provided in Fig. 4A reveals that the rank order of insertion efficiency opposite the abasic site is 5-NIMP >> Ind-MP $\sim$ dAMP. Quantitative analyses reveal that under these conditions, the rate of Ind-MP insertion opposite the lesion is 2.5-fold higher than dAMP insertion (Fig. 4B). However, the rate of Ind-MP insertion is at least 40 -fold lower compared to that of 5-NIMP insertion (Fig. 4B).

While it is clear that removal of the nitro group greatly reduces the efficiency of insertion opposite an abasic site, these data alone cannot identify if this reduction reflects a perturbation in nucleotide binding, phosphoryl transfer, or both. Therefore, we determined the kinetic parameters for Ind-TP during insertion opposite the abasic site by monitoring rates of insertion at varying Ind-TP concentrations $(5-500 \mu \mathrm{M})$. Time courses in product formation at each concentration of Ind-TP tested were linear and devoid of an initial "burst" in primer elongation (Fig. 5A). The lack of a detectable burst indicates that phosphoryl transfer or more likely, the conformational 
Table 1 Summary of ${ }^{1} \mathrm{H}$ and ${ }^{13} \mathrm{C}$ chemical shifts and coupling constants for the furanoside and pyranosides synthesized in this study

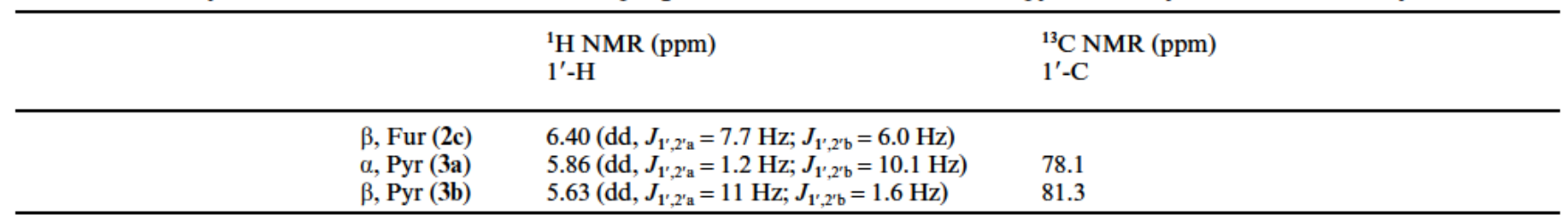

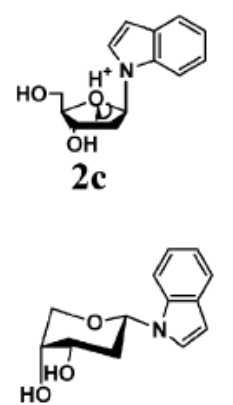

3a
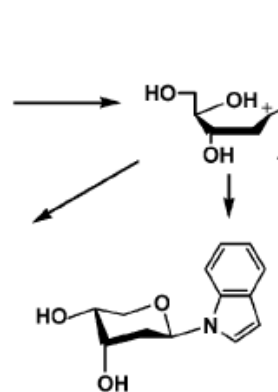

$3 \mathbf{b}$

Fig. 3 Proposed mechanism accounting for the formation of contaminating $\alpha$ - and $\beta$-pyranosides that occur during the synthesis of indolyl-2'-deoxyriboside triphosphate. Indolyl-2'-deoxyriboside (2c) undergoes acid-catalyzed ring opening. The intermediate isomerizes to yield the $\alpha$ - and $\beta$-pyranosides (3a and 3b). The $\alpha$-isomer of indolyl-2'deoxyriboside is not detected.

\section{A}
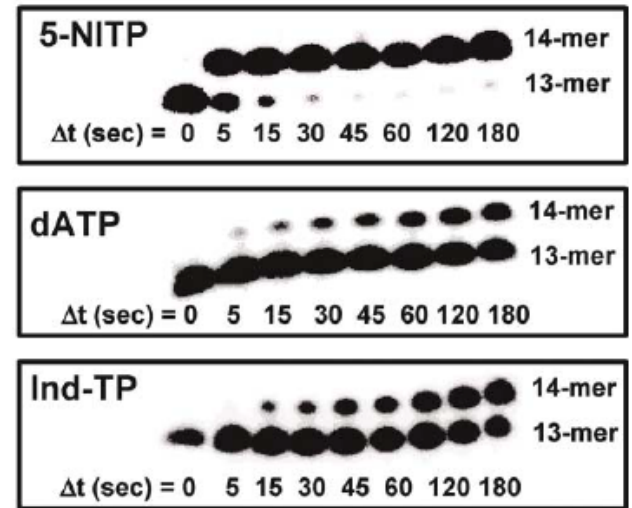

B

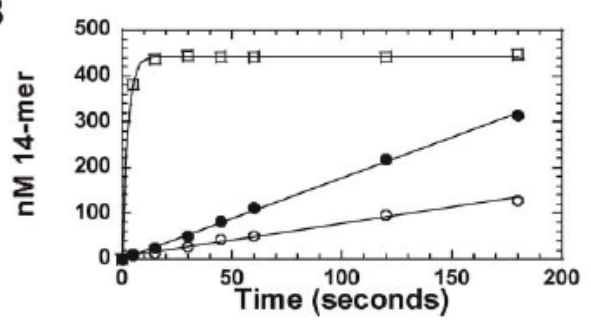

Fig. 4 Insertion of various nucleoside triphosphates opposite an abasic site. (A) DNA synthesis was monitored using $10 \mathrm{nM}$ gp43, 500 nM 13/20SP-mer DNA substrate, and $350 \mu \mathrm{M}$ dATP, $350 \mu \mathrm{M}$ 5-NITP, or $350 \mu \mathrm{M}$ Ind-TP, respectively. The reaction was then terminated at various times by the addition of $200 \mathrm{mM}$ EDTA at times ranging from 0 to 120 seconds. (B) Rates of Ind-MP and dAMP insertion opposite an abasic site were calculated from the linear portions of the curves. The rate using Ind-TP $(O)$ is $1.8 \mathrm{nM} \mathrm{s}^{-1}$ while that using dATP $(O)$ is 0.78 $\mathrm{nM} \mathrm{s}{ }^{-1}$. The rate of 5-NIMP ( $\square$ ) insertion is estimated to be at least 80 $\mathrm{nM} \mathrm{s}{ }^{-1}$ since nearly all DNA substrate $(\sim 400 \mathrm{nM})$ is converted to product within 5 seconds, the first time point taken.

change step preceding phosphoryl transfer, is the rate-limiting step for enzyme turnover. ${ }^{24,} 27$

The rate of primer elongation was plotted as a function of Ind-TP concentration (Fig. 5B) and the data were fit to the Michaelis-Menten equation to obtain values corresponding to $k_{\text {cat }}, K_{\mathrm{m}}$, and $k_{\text {cat }} / K_{\mathrm{m}}$ (Table 2). As predicted by the base-stacking model, removal of $\pi$-electron density dramatically reduces the

A

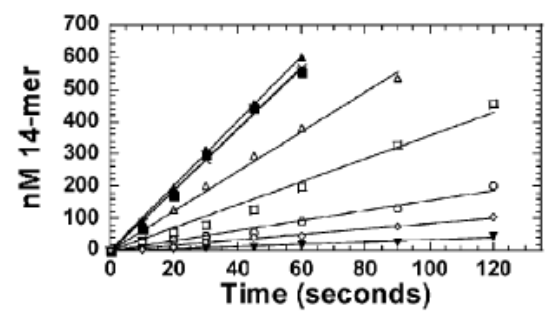

B

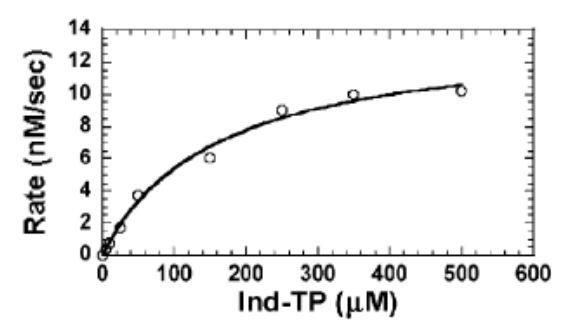

Fig. 5 Dependency of Ind-TP concentration on the steady-state rate of primer elongation as measured under pseudo-first order reaction conditions. (A) gp43 (50 nM) and 5'-labeled 13/20SP-mer (1000 nM) were preincubated, mixed with increasing concentrations of $\mathrm{Mg}^{2+}$ :IndTP to initiate the reaction, and quenched with $200 \mathrm{mM}$ EDTA at variable times (5-120 seconds). The insertion of Ind-MP was analyzed by denaturing gel electrophoresis. Ind-TP concentrations were $5 \mu \mathrm{M}$ $(\mathbf{\nabla}), 10 \mu \mathrm{M}(\diamond), 25 \mu \mathrm{M}(\bigcirc), 50 \mu \mathrm{M}(\square), 150 \mu \mathrm{M}(\triangle), 250 \mu \mathrm{M}(\mathbf{\square}), 350$ $\mu \mathrm{M}(\boldsymbol{\Delta})$, and $500 \mu \mathrm{M}(\times)$. The solid lines represent the fit of the data to a straight line. (B) The observed rates for Ind-MP insertion $(O)$ were plotted against Ind-TP concentration and fit to the Michaelis-Menten equation to determine values corresponding to $K_{\mathrm{m}}$ and $k_{\text {cat }}$.

catalytic efficiency for Ind-TP insertion $\left(k_{\text {cat }} / K_{\mathrm{m}}=1.93 * 10^{3} \mathrm{M}^{-1}\right.$ $\mathrm{s}^{-1}$ ) by approximately 3600 -fold compared to that for 5-NIMP insertion $\left(k_{\mathrm{pol}} / K_{\mathrm{d}}=7.0^{*} 10^{6} \mathrm{M}^{-1} \mathrm{~s}^{-1}\right){ }^{24}$ Surprisingly, the binding affinity for Ind-TP is only 8-fold weaker than that of 5 -NITP. ${ }^{24}$ The difference in binding affinity corresponds to an unfavorable change in relative free energy, $\Delta \Delta G$, of $1.23 \mathrm{kcal} \mathrm{mol}^{-1}$. This value was calculated using the equation $\Delta \Delta G=R T \ln K$, where $R=1.9872 \mathrm{cal} / \mathrm{mol}^{*} \mathrm{~K}, T=298 \mathrm{~K}$, and $K$ is the ratio of respective kinetic equilibrium dissociation or kinetic rate constants. In this specific instance, the ratio is defined as $K_{\text {Ind-MP }} / K_{\text {5-NIMP }}$ measured for the enzyme-catalyzed insertion of either non-natural nucleoside opposite an abasic site. More striking, however, is the larger 450 -fold reduction in the polymerization rate constant for Ind-MP insertion opposite an abasic site as compared to that for 5-NITP. ${ }^{24}$ The ratio of $k_{\text {cat Ind-MP }} / k_{\text {pol }}$ 5-NIMP provides a decrease in $\Delta \Delta G$ of 3.62 $\mathrm{kcal} \mathrm{mol}{ }^{-1}$ that likely reflects additional energetic demands of the conformational change step preceding phosphoryl transfer.

We interpret these energetic differences to reflect the contributions of base-stacking interactions rather than desolvation. If desolvation was the preeminent driving force, then the efficiency of nucleotide insertion should be closely correlated with nucleobase hydrophobicity. The calculated oil-to-water partition coefficient ( $\log \mathrm{P}$ value) for indole is +1.64 and is remarkably similar to the value of +1.67 calculated for 5 -nitroindole. The value of +1.67 reported here differs from that of +2.46 reported by Guckian et al. ${ }^{37}$ and reflects using the free nucleobase (this study) rather than the nucleobase containing a methyl group at the N1 position of the purine analog. ${ }^{37}$ Regardless of the nuances in methodology, identical 
Table 2 Summary of kinetic parameters for the incorporation of Ind-TP catalyzed by gp43 ${ }^{a}$.

\begin{tabular}{llll}
\hline DNA substrate & $k_{\text {cat }}\left(\mathrm{s}^{-1}\right)$ & $K_{\mathrm{m}}(\mu \mathrm{M})$ & $k_{\text {cat }} / K_{\mathrm{m}}\left(\mathrm{M}^{-1} \mathrm{~s}^{-1}\right)$ \\
\hline $13 / 20_{\mathrm{SP}}$-mer & $0.28 \pm 0.07$ & $145 \pm 10$ & $1.93^{*} 10^{3}$ \\
& $\left(+3.62 \mathrm{kcal} \mathrm{mol}^{-1}\right)^{b}$ & $\left.(+1.23 \mathrm{kcal} \mathrm{mol})^{-1}\right)$ & $\left(+4.85 \mathrm{kcal} \mathrm{mol}^{-1}\right)$ \\
$13 / 20_{\mathrm{A}}-\mathrm{mer}$ & $0.13 \pm 0.03$ & $100 \pm 15$ & $1.30^{*} 10^{3}$ \\
& $\left(+2.09 \mathrm{kcal} \mathrm{mol}^{-1}\right)$ & $\left(+0.88 \mathrm{kcal} \mathrm{mol}^{-1}\right)$ & $\left(+2.97 \mathrm{kcal} \mathrm{mol}^{-1}\right)$ \\
$13 / 20_{\mathrm{C}}-\mathrm{mer}$ & $0.074 \pm 0.02$ & $195 \pm 20$ & $0.38^{*} 10^{3}$ \\
& $\left(+0.33 \mathrm{kcal} \mathrm{mol}^{-1}\right)$ & $\left(+1.00 \mathrm{kcal} \mathrm{mol}^{-1}\right)$ & $\left(+1.33 \mathrm{kcal} \mathrm{mol}^{-1}\right)$ \\
$13 / 20_{\mathrm{G}}-\mathrm{mer}$ & $0.027 \pm 0.01$ & $180 \pm 15$ & $0.13^{*} 10^{3}$ \\
& $\left(+0.88 \mathrm{kcal} \mathrm{mol}^{-1}\right)$ & $\left(+1.71 \mathrm{kcal} \mathrm{mol}^{-1}\right)$ & $\left(+2.59 \mathrm{kcal} \mathrm{mol}^{-1}\right)$ \\
$13 / 20_{\mathrm{T}}-\mathrm{mer}$ & $0.29 \pm 0.1$ & $230 \pm 30$ & $1.26^{*} 10^{3}$ \\
& $\left(+0.67 \mathrm{kcal} \mathrm{mol}^{-1}\right)$ & $\left(+1.92 \mathrm{kcal} \mathrm{mol}^{-1}\right)$ & $\left(+2.59 \mathrm{kcal} \mathrm{mol}^{-1}\right)$
\end{tabular}

${ }^{a}$ Assays were performed using $50 \mathrm{nM}$ gp43, $1000 \mathrm{nM}$ DNA substrate, and variable concentrations of Ind-TP in the presence of $10 \mathrm{mM} \mathrm{Mg}$ acetate. ${ }^{b} \Delta \Delta G$ values were calculated using the equation $\Delta \Delta G=R T \ln K$, where $R=1.9872 \mathrm{cal} / \mathrm{mol}^{*} \mathrm{~K}, T=298 \mathrm{~K}$, and $K$ is the ratio of respective kinetic equilibrium or rate constants for the enzyme-catalyzed insertion of Ind-MP or 5-NIMP opposite an abasic site.

trends in hydrophobicity in $\log \mathrm{P}$ values for natural and non-natural nucleobases are seen (data not shown). In general, the inability to draw a distinct correlation between the kinetics of nucleoside insertion and hydrophobicity detracts from a model solely involving desolvation as the driving force for enhanced translesion DNA synthesis.

Surprisingly, the catalytic efficiency for Ind-MP insertion opposite the abasic site is nearly identical to that reported for dAMP insertion (compare $1.93^{*} 10^{3} \mathrm{M}^{-1} \mathrm{~s}^{-1}$ for Ind-TP with $4.3^{*} 10^{3} \mathrm{M}^{-1} \mathrm{~s}^{-1}$ for dATP). ${ }^{27}$ As above, the catalytic efficiency for insertion does not correlate well with desolvation properties since Ind-MP is significantly more hydrophobic than dAMP (compare $\log \mathrm{P}$ values of +1.64 and -1.45 for indole and adenosine, respectively). Collectively, these analyses suggest that hydrogen bonding potential or desolvation capabilities of the nucleoside do not play a significant role in facilitating translesion DNA synthesis.

\section{Enzymatic insertion opposite templating nucleobases}

While devoid of any hydrogen-bonding functional groups, Ind-TP is a purine mimic and should be preferentially inserted opposite the pyrimidines, $\mathrm{C}$ and $\mathrm{T}$. This prediction was tested by measuring the insertion kinetics of Ind-MP opposite each of the four natural template bases. The corresponding values for $k_{\text {cat }}, K_{\mathrm{m}}$, and $k_{\text {cat }} / K_{\mathrm{m}}$ are summarized in Table 2. Although the $k_{\text {cat }} / K_{\mathrm{m}}$ values vary 10 -fold depending upon the composition of the template nucleobase, the expected correlation between catalytic efficiency and shape complementarity of the formed base pair is not always observed. For example, the low catalytic efficiency for Ind-MP insertion opposite $\mathrm{G}$ is expected since this represents an unfavorable purine-purine mispair. However, the near identical $k_{\text {cat }} / K_{\mathrm{m}}$ value measured for Ind-MP insertion opposite $\mathrm{C}$ contradicts this prediction. Similarly, the nearly identical catalytic efficiencies for Ind-MP insertion opposite either $\mathrm{T}$ or A cannot be adequately explained by the geometrical constraints of the formed base pair. It is possible that the preferential insertion at these positions reflects the contributions of nearest-neighbor stacking effects. ${ }^{38-40}$ However, further experimentation is required to unambiguously prove this.

Another surprising feature is that the $K_{\mathrm{m}}$ value for Ind-TP does not significantly vary as a function of template nucleobase composition. This unexpected phenomenon was also observed during 5-NIMP insertion opposite natural nucleobases in which the $K_{\mathrm{d}}$ value for 5-NITP was $\sim 20 \mu \mathrm{M}$ regardless of template base composition. ${ }^{24}$ It appears that both 5-NIMP and Ind-MP can be indiscriminately inserted opposite any templating nucleobase. However, removal of the "bulky" nitro group actually decreases ground state binding affinity since the $K_{\mathrm{m}}$ values measured for Ind-MP insertion are approximately 10 -fold higher than for 5-NITP. ${ }^{24}$

Why does removal of the nitro group affect catalytic efficiency without affecting selectivity? One possibility is that the indole portion of the nucleobase possesses enough size and/or base-stacking requirements for non-selective binding to the polymerase:DNA complex while the 5-nitro group provides $\pi$-electrons which contribute to affinity. To provide quantitative insight into this potential model, the absolute differences in insertion efficiency between Ind-TP and 5-NITP were converted to corresponding changes in $\Delta \Delta G$ values by using the ratio of $k_{\text {cat }} / K_{\mathrm{m}}$ to $k_{\text {pol }} / K_{\mathrm{d}}$ values. As summarized in Table 2 , the most unfavorable change in $\Delta \Delta G$ value for overall catalytic efficiency is $+4.85 \mathrm{kcal} \mathrm{mol}^{-1}$ which is observed during insertion opposite the abasic site. We hypothesize that removal of the nitro group reduces base-stacking interactions with the polymerase as well as with nucleic acid. The details of this model are provided in Fig. 6. The favorable insertion of 5-NITP suggests that the polymerase utilizes $\pi-\pi$ stacking interactions between the conjugated ring system of the incoming dNTP with a defined cluster of aromatic amino acids to provide selectivity and affinity. The higher $K_{\mathrm{m}}$ values for Ind-TP coincide well with the reduction in $\pi$-electron conjugation. Indeed, the proposed existence of a "non-specific" binding dNTP site is strengthened since the $K_{\mathrm{m}}$ value for Ind-TP remains nearly identical despite variations in the coding and non-templating features of the template.

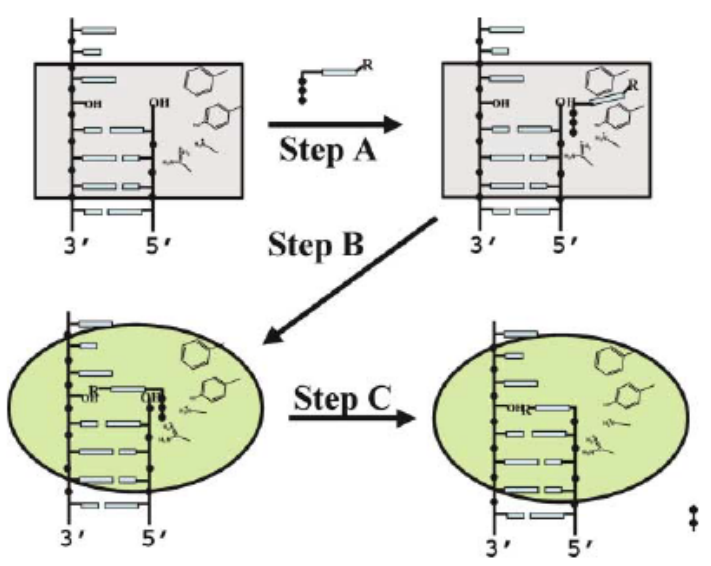

Fig. 6 Proposed model for the enzymatic insertion of non-natural nucleotides opposite an abasic site. Step A depicts the binding of nonnatural nucleotide into the putative non-specific binding pocket lined with aromatic amino acids. Step B represents the conformational change preceding phosphoryl transfer required to place the triphosphate moiety in close proximity with the positively charged amino acids as well as to stack the nucleobase portion of the incoming dNTP into the hydrophobic environment of the interior of the duplex DNA. Step $\mathrm{C}$ represents the phosphoryl transfer step required for elongation of the primer strand. In this mechanism, the functionality present at the 5position of indole affects the dynamics of Step A (ground state binding) and Step B (conformational change step). Specifically, the nitro moiety containing $\pi$-electron density is proposed to enhance binding as well as the rate of the conformational change preceding chemistry. The reduced catalytic efficiency for Ind-MP insertion is proposed to reflect the removal of the $\pi$-electron density. 
Although removal of the nitro group adversely affects binding affinity by $1-2 \mathrm{kcal} \mathrm{mol}^{-1}$, the predominant effect is a reduction in the $k_{\mathrm{pol}}$ step that presumably reflects the conformational change preceding phosphoryl transfer. The dynamics of this kinetic step are influenced by $\pi$-electron density ${ }^{24}$ since removal of the nitro group reduces the rate of the conformational change step by 450 -fold. We previously proposed that this enzyme-mediated conformational change reflects the transfer of an aromatic nucleobase from the enzyme into the aromatic environment of the duplex DNA. ${ }^{24}$ If correct, then the $\Delta \Delta G$ value of $3.62 \mathrm{kcal} \mathrm{mol}^{-1}$ associated with the conformational change step reflects energetic stabilization from basestacking and not from hydrogen-bonding and/or geometrical constraints.

\section{"Universal" nucleobase applications}

The lack of selectivity for Ind-MP insertion opposite natural template nucleobases suggests that this nucleoside is a "universal" base. This feature could be beneficial for hybridization applications such as universal primers for PCR amplification, DNA sequencing, and ligation reactions $\left(\right.$ reviewed in ${ }^{41}$ ). However, these applications depend upon the ability of the polymerase to extend beyond the "universal" base once it is incorporated into nucleic acid. Our first endeavor was to evaluate if the non-natural nucleobase would enhance the efficiency of translesion DNA synthesis. We previously demonstrated that extension beyond an abasic site is significantly slower than extension from a normal base pair. $27,42-44$ However, the kinetics of elongation are more efficient when purines are placed opposite the DNA lesion as opposed to pyrimidines. ${ }^{27}$ Since Ind-MP is a purine mimic, it was predicted that the polymerase should easily extend beyond the formed mispair.

We used the experimental protocol outlined in Fig. 7A to first measure the ability of gp43 to extend beyond a dAMP:abasic site mispair. The polymerase:DNA complex was first incubated with $35 \mu \mathrm{M}$ dATP for 5 minutes which is enough time to allow

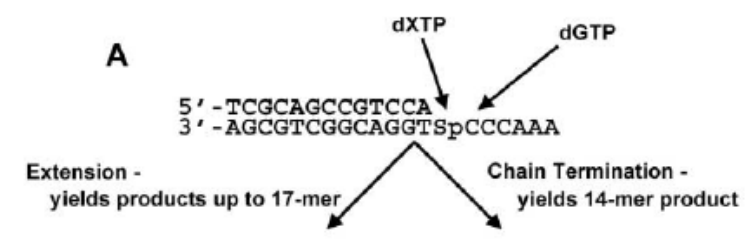

$\begin{array}{ll}\text { 5' -TCGCAGCCGTCCA X GGG } & \text { 5' -TCGCAGCCGTCCAX } \\ \text { 3'-AGCGTCGGCAGGTSPCCCAAA } & \text { 3'-AGCGTCGGCAGGTSPCCAAA }\end{array}$

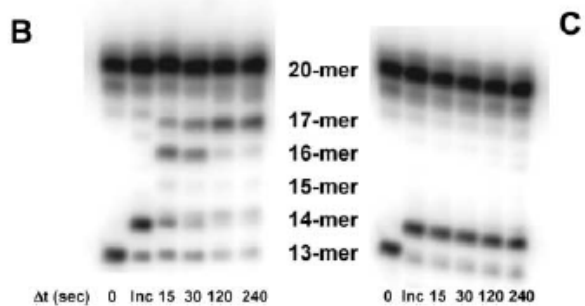

C

Fig. 7 Chain termination capabilities of indolyl-2'-deoxyriboside triphosphate. (A) Experimental paradigm used to measure insertion and extension beyond an abasic site lesion. gp $43(1 \mu \mathrm{M})$ and $5^{\prime}$-labeled $13 / 20$ SP-mer $(500 \mathrm{nM})$ were preincubated, mixed with $35 \mu \mathrm{M}$ dATP or $150 \mu \mathrm{M}$ Ind-TP to initiate the reaction. After 5 minutes, an aliquot of the reaction was quenched with $200 \mathrm{mM}$ EDTA (denoted as Inc) to measure insertion opposite the lesion. $500 \mu \mathrm{M}$ dGTP was then added and aliquots of the reaction were quenched with $200 \mathrm{mM}$ EDTA at variable times (15-180 s). Product formation was analyzed by denaturing gel electrophoresis. (B) gp43 is able to extend beyond the dAMP:abasic site since elongation of 13/20SP-mer to the 17/20SP-mer is observed in the presence of dATP and dGTP. Note that the 20-mer band present in all lanes results from ${ }^{32} \mathrm{P}$-labelling of the template strand and is provided as a loading control. (C) Although gp43 inserted Ind-MP opposite the abasic site, the polymerase is unable to elongate the mispair due to the lack of extension beyond the formed 14-mer. nearly all of the primer to be elongated by only one base, i.e., conversion of 13-mer to 14-mer. After this time frame, $500 \mu \mathrm{M}$ dGTP was added to allow extension beyond the enzymatically formed dAMP:abasic site mispair. As shown in Fig. 7B, extension beyond the formed dAMP:abasic site occurs with low efficiency since a mixture of polymerization products ranging from 15- to 17-mers accumulate. In fact, the low rate constant of $\sim 0.03 \mathrm{~s}^{-1}$ measured here for extension beyond the dAMP: abasic site mispair is consistent with previously published values. ${ }^{27}$

The ability of gp43 to extend beyond the Ind-MP:abasic site mispair was next evaluated using a similar approach. The polymerase:DNA complex was first incubated with $150 \mu \mathrm{M}$ Ind-TP for 5 minutes prior to the addition of $500 \mu \mathrm{M}$ dGTP (Fig. 7C). As expected, the DNA is elongated as illustrated by the accumulation of 14-mer. However, the DNA cannot be elongated even if the polymerase is supplied with $500 \mu \mathrm{M}$ dGTP (Fig. 7C) or $2 \mathrm{mM}$ dGTP (data not shown). Increasing the reaction time up to 10 minutes has no effect on extension (data not shown). The inability to extend beyond Ind-MP directly contrasts extension beyond the dAMP:abasic mispair and suggests that Ind-MP is a chain terminator of DNA synthesis.

The ability of the polymerase to extend beyond an abasic site is influenced by the base-stacking capabilities of the nucleobase placed opposite the lesion. ${ }^{27}$ The lack of extension beyond the Ind-MP:abasic site could reflect the low base-stacking capabilities of the non-natural nucleobase, a phenomenon that likely contributes to the low catalytic efficiency for its insertion. It should be noted that gp43 cannot extend beyond Ind-MP even when it is placed opposite any of the four natural nucleobases (data not shown). This is somewhat surprising since Ind-MP:C and Ind-MP:T pairs are predicted to be sterically equivalent to natural base-pairs. These data alone cannot exclude the possibility that the size and shape of the formed mispair affect the ability of the polymerase to extend it. However, a more likely explanation is that the lack of functional groups on Ind-MP adversely affects the kinetics of elongation. Indeed, several reports indicate that removing or perturbing the functional groups residing in the minor groove of duplex DNA severely retards the efficiency of elongation. ${ }^{45-48}$ This could affect the ability of the polymerase to translocate to the next template position or could cause the enzyme to partition into its associated exonuclease active site in an attempt to remove the non-natural mispair. It will prove interesting to resolve this issue by evaluating the contributions of hydrogen bonding, base-stacking, and shape complementarity to the dynamics of translocation and exonuclease proofreading.

\section{Conclusions}

In this report, we describe the synthesis and characterization of indolyl-2'-deoxyriboside triphosphate, a non-natural nucleoside possessing many features of a truly "universal" nucleobase. We have demonstrated, using the bacteriophage T4 DNA polymerase, that Ind-MP is inserted opposite an abasic site much less effectively compared to 5 -NIMP. ${ }^{24}$ The reduced catalytic efficiency of Ind-MP insertion results from minor perturbations in nucleotide binding coupled with a larger decrease in the rate of the conformational change that precedes chemistry. The inability to correlate nucleobase hydrophobicity and catalytic efficiency for insertion between these non-natural nucleobases suggests that desolvation plays a minimal role in insertion opposite an abasic site. More likely, the removal of the nitro group and associated $\pi$-electron density reduces basestacking interactions of Ind-MP between the enzyme ( $K_{\mathrm{d}}$ effect) as well as with nucleic acid ( $k_{\text {pol }}$ effect).

We argue that shape complementarity plays a minimal role in optimizing catalytic efficiency with the bacteriophage DNA polymerase. This statement is justified since purine:purine 
mispairs such as Ind-MP:A and Ind-MP:G are formed with nearly identical catalytic efficiencies as the more preferred purine:pyrimidine mismatches that include Ind-MP:C and IndMP:T. In this regard, the requirements for base selection and insertion by the $\mathrm{T} 4$ polymerase appear to be vastly different compared to other polymerases such as the Klenow fragment of Escherichia coli ${ }^{14-16}$ and the Taq DNA polymerase. ${ }^{21}$ Several independent laboratories have demonstrated that these polymerases effectively insert non-hydrogen bonding base analogs opposite natural template bases. ${ }^{14-22}$ In most cases, however, isosteric analogs are preferentially inserted opposite their shape complement. ${ }^{14,16,17}$ The facile insertion of difluorotoluene opposite adenine ${ }^{14}$ and the dual specificity of 4-methylpyridin2-one insertion opposite adenine or guanine ${ }^{49}$ highlight the importance of shape complementarity in polymerization efficiency. However, a more appropriate comparison of catalytic strategies can be made for the insertion of purine-mimics opposite templating and non-templating lesions. As mentioned earlier, the overall catalytic efficiency $\left(V_{\max } / K_{\mathrm{m}}\right)$ for dPTP insertion opposite an abasic site is 100 -fold higher than dAMP insertion opposite the same lesion. Surprisingly, Klenow fragment also inserts the dPTP opposite natural templating positions with nearly identical catalytic efficiencies. ${ }^{15}$ Specifically, the $K_{\mathrm{m}}$ value for dPTP varies slightly among templating positions while the $V_{\max }$ is significantly reduced compared to the insertion of the natural complementary partner. The differences in catalytic efficiency could arguably reflect the role of size constraints during polymerization. Results have also been reported with other non-natural nucleobases using Klenow fragment as the model DNA polymerase. Morales and $\mathrm{Kool}^{16}$ demonstrated that the catalytic efficiency for the insertion of 9-methyl- $1 \mathrm{H}$-imidazo[4,5- $b$ ]pyridine opposite $\mathrm{C}$ or $\mathrm{T}$ is 100 -fold more efficient than insertion opposite $\mathrm{A}$ or $\mathrm{G}$ Similar results have also been obtained by Tae et $a .^{50}$ using 7-aza-indole nucleoside triphosphate as the isosteric analog. Collectively, the data for Klenow fragment reveal that isosteric analogs are effectively and preferentially inserted opposite their complementary templating partner. This suggests that Klenow fragment employs a mechanism invoking geometrical alignment of the incoming nucleobase with the template base to optimize polymerization.

Despite the similarities in substrate utilization, ${ }^{51}$ overall kinetic mechanism (reviewed in ${ }^{52}$ ), and tertiary enzyme structure (reviewed in ${ }^{53}$ and ${ }^{54}$ ), it appears that DNA polymerases employ different strategies to achieve efficient polymerization. We argue that the observed kinetic differences between the T4 DNA polymerase and Klenow fragment reflect subtle structural differences in the geometry/orientation of aromatic amino acids that are conserved among various classes of DNA polymerases. Fig. 8 provides a structural comparison of the active sites of the bacteriophage RB69 DNA polymerase (homologous to the bacteriophage T4 enzyme) ${ }^{55}$ and KlenTaq DNA polymerase. ${ }^{56}$ It should be noted that the DNA polymerases from bacteriophage T4 and RB69 possess $\sim 60 \%$ sequence identity and $\sim 85 \%$ sequence conservation. ${ }^{57}$ The high conservation in amino acid sequence and functionality ${ }^{58}$ implies that the two bacteriophage polymerases are structurally homologous. While all DNA polymerases examined to date possess the same overall molecular architecture (palm, thumb, and fingers subdomains), ${ }^{53,54}$ it is clear from visual inspection of Fig. 8 that the active site of each DNA polymerase is organized differently. Specifically, we have examined the orientation of aromatic residues that reside within $6 \AA$ of the primer-template junction. The structure for the bacteriophage DNA polymerase shows that Y416, Y567, and Y391 form a defined cluster near the active site that could be involved in the proposed "non-selective" dNTP binding site Note that F282 is also located in close proximity to the template and incoming dNTP and could also play a stabilizing role in binding and/or catalysis. In contrast, the active site of KlenTaq is dramatically different with respect to the orien-

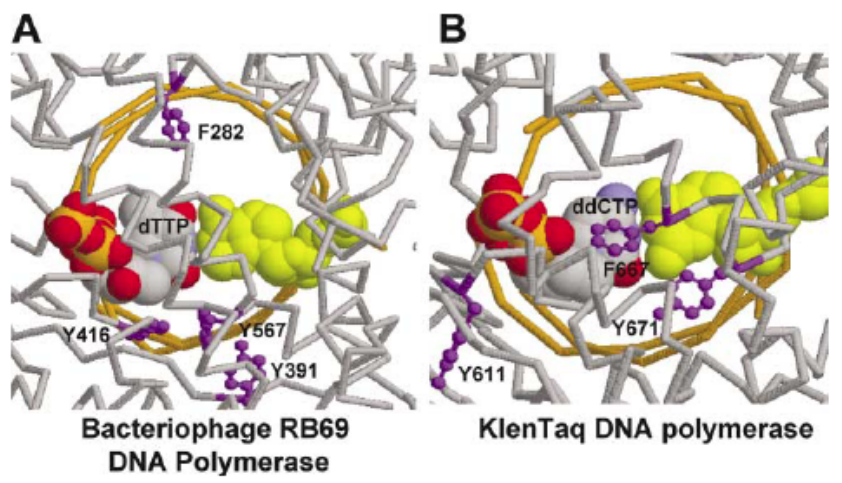

Fig. 8 Active site structures of the bacteriophage RB69 DNA polymerase (A) and KlenTaq DNA polymerase (B). The backbone of each polymerase is colored gray while duplex DNA is colored gold. For clarity, the nucleobase pair at the primer-template junction is displayed as a space-filled model. The aromatic amino acids that lie within 6 angstroms of the primer-template junction are colored purple. As discussed in the text, the distinct difference in orientation of these aromatic amino acids in each polymerase's active site is proposed to reflect differences in catalytic strategies used by each polymerase to achieve polymerization efficiency and fidelity.

tation/arrangement of these conserved aromatic amino acids. Although Y661 in KlenTaq is analogous to Y416 in the bacteriophage DNA polymerase, Y661 is oriented in a distinctly different arrangement and is pointed away from the primertemplate junction. Another interesting difference is the positioning of Y671 of KlenTaq which lies on the template side of the forming base pair. While this position favors base-stacking interactions with the templating base in KlenTaq, no such interaction is observed in the structure of the bacteriophage polymerase. Finally, F667 is the only aromatic amino acid that actually protrudes substantially into the active site of KlenTaq. Quite surprisingly, its position could form part of the minor groove "back wall" of the enzyme which could be involved in steric gating of the incoming dNTP. However, its position may also provide a good parallel stacking orientation with the incoming dNTP and thus could play a dual role in maintaining polymerization fidelity. The collective differences in the orientation and proximity of these conserved aromatic amino acids provide a reasonable explanation to account for the subtle differences in insertion kinetics between polymerases.

A final point of discussion is with respect to the potential therapeutic applications of non-natural nucleoside analogs. Nucleoside analogs such as azidothymidine (AZT) and 1- $\beta-D-$ arabinofuranosyl cytidine (AraC) are effective chemotherapeutic agents since they function as chain terminators of DNA replication (reviewed in ${ }^{59}$ ). This ability results from alterations in the ribose moiety while the nucleobase portion remains identical to that of a natural nucleoside. In this report, we demonstrate that the Ind-TP also possesses unique chain termination capabilities. Equally important, Ind-MP does not display a preference for insertion. We propose that these features may provide a useful paradigm toward re-designing nucleoside analogs as effective chemotherapeutic agents. For example, the lack of functional groups present on the nonnatural nucleobase allows it to be inserted but not extended. This provides a new approach to develop chain terminators by focusing on the nucleobase portion of the analog rather than on the ribose moiety. Likewise, the apparent lack of selectivity for insertion would theoretically increase its efficacy since the nucleoside could be inserted at any template position. Unfortunately, the high $K_{\mathrm{m}}$ value for Ind-MP is indicative of low potency. This low potency would limit its effectiveness since natural dNTPs, having low $K_{\mathrm{d}}$ values, would preferentially bind to the polymerase and out compete the non-natural nucleoside for insertion. Current efforts are underway to improve the potency of these non-natural nucleosides by introducing various functional groups on the indole moiety. 


\section{Experimental}

\section{Synthesis}

Tributylammonium pyrophosphate was purchased from Sigma. All the other reagents were purchased from ACROS. Trimethy phosphate and tributylamine were dried over $4 \AA$ molecular sieves. DMF was distilled from ninhydrin, stored in $4 \AA$ molecular sieves. Preparative reverse phase HPLC was used to purify triphosphate using a 300 pore size $\mathrm{C}-18$ column from Vydac $(22 \mathrm{~mm} \times 300 \mathrm{~mm})$; buffer A: $0.1 \mathrm{M}$ TEAB; buffer B: $35 \% \mathrm{ACN}$ in $0.1 \mathrm{M}$ TEAB, linear gradient of from $4 \%$ to $80 \%$ B within

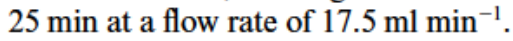

All NMR spectra were recorded in a Gemini-300 FT NMR spectrometer. Proton chemical shifts are reported in ppm downfield from tetramethylsilane (TMS). Coupling constants $(J)$ are reported in hertz $(\mathrm{Hz}) .{ }^{31} \mathrm{P}-\mathrm{NMR}$ spectra were taken in $\mathrm{D}_{2} \mathrm{O}$ in the presence of $50 \mathrm{mM}$ Tris $(\mathrm{pH} 7.5)$ and 2 mM EDTA $85 \%$ phosphoric acid was used as external standard. Ultraviolet quantification of triphosphate was performed on a Beckman DU $^{\mathbb{0}}$-70. Fast atom bombardment mass spectra (FAB-MS) were obtained with a Kratos MS-25RFA spectrometer. Highresolution electrospray mass spectrometry (negative ion) was performed on an IonSpec HiRes ESI-FTICRMS using the facilities at the University of Cincinnati.

\section{1-(2-Deoxy-p-D-erythro-pentafuranosyl)-1 $H$-indole (2c)}

A solution of indole $(0.6 \mathrm{~g}, 5 \mathrm{mmol})$ in acetonitrile $(120 \mathrm{~mL})$ was treated with sodium hydride $(0.244 \mathrm{~g}, 6 \mathrm{mmol})$ and the mixture stirred at room temperature for 30 minutes. 1-Chloro-2deoxy-3,5-di-O $O$ - -toluoyl- $\alpha$-D-erythro-pentofuranose $(2.4 \mathrm{~g}$, $6 \mathrm{mmol}$ ) was then added and the reaction mixture was stirred overnight at room temperature, filtered and evaporated to dryness. The crude product was purified by flash silica gel column chromatography using toluene to give a colorless syrup.

To a solution of the obtained compound $(1.4 \mathrm{~g})$ in methanol (40 mL) was added sodium methoxide until $\mathrm{pH} \sim 12$ was attained. The mixture was stirred overnight at room temperature and then evaporated. The nucleoside was purified by flash chromatography on silica using dichloromethane and methanol as the solvents $(95: 5)$.

${ }^{1} \mathrm{H}-\mathrm{NMR}(\mathrm{ppm})$ (DMSO-d $\left.{ }_{6}\right) 2.21(\mathrm{~m}, 1 \mathrm{H}), 2.45(\mathrm{~m}, 1 \mathrm{H})$, $3.46-3.56(\mathrm{~m}, 2 \mathrm{H}), 3.80-3.85(\mathrm{~m}, 1 \mathrm{H}), 4.35(\mathrm{~m}, 1 \mathrm{H}), 4.89$ (t, $J=6,1 \mathrm{H}), 5.29(\mathrm{~d}, J=4,1 \mathrm{H}), 6.39(\mathrm{dd}, J=1.7,7,1 \mathrm{H}), 6.51$ (d, $J=4,1 \mathrm{H}), 7.02-7.20(\mathrm{~m}, 2 \mathrm{H}), 7.54-7.60(\mathrm{~m}, 3 \mathrm{H})$.

${ }^{13}$ C-NMR (ppm) (DMSO-d ${ }_{6}$ ) 61.87, 70.72, 84.25, 86.82, 102.22, 110.16, 119.64, 120.43, 121.41, 125.31, 128.49, 135.70 .

Upon irradiation at $6.39 \mathrm{ppm}$ for the anomeric hydrogen, the NOE was observed at 3.80-3.85(H-4') along with $2.21\left(\mathrm{H}-2^{\prime} \alpha\right)$, $2.45\left(\mathrm{H}-2^{\prime} \beta\right), 7.54-7.6(\mathrm{H}-2$ and $\mathrm{H}-7)$.

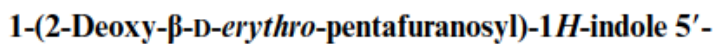 triphosphate (2d, Ind-TP)}

Phosphorus oxychloride ( $16 \mu \mathrm{l}, 0.17 \mathrm{mmol})$ was added dropwise to a stirred and cooled $\left(0-4{ }^{\circ} \mathrm{C}\right)$ solution of indole- $2^{\prime}$-deoxynucleoside ( $35 \mathrm{mg}, 0.15 \mathrm{mmol}$ ) and proton sponge ( $48 \mathrm{mg}, 0.22$ $\mathrm{mmol})$ in trimethyl phosphate $(0.75 \mathrm{ml})$. After 2 hours, the reaction mixture was simultaneously treated with $0.5 \mathrm{M}$ of tributylammonium pyrophosphate $(400 \mathrm{mg}, 0.75 \mathrm{mmol})$ in DMF, and tributylamine $(0.18 \mathrm{ml}, 0.75 \mathrm{mmol})$. After stirring at room temperature for $10 \mathrm{~min}$, the reaction mixture was neutralized with $1.0 \mathrm{M}$ TEAB $(20 \mathrm{ml})$, and then stirred at room temperature. After 2 hours, the reaction mixture was evaporated under reduced pressure at $37^{\circ} \mathrm{C}$ to about $2 \mathrm{ml}$, and was purified by reverse phase HPLC (the elution system is given in the general method). The desired triphosphate was eluted at $52 \% \mathrm{~B}$ (16 min retention time). The product was then evaporated to $1 \mathrm{ml}$ under reduced pressure at $37^{\circ} \mathrm{C}$, resuspended in $5 \mathrm{ml}$ of methanol and then evaporated to dryness. This process was repeated 3 times. The final product was dissolved and stored in $10 \mathrm{mM}$ TrisHCl, $\mathrm{pH}$ 7.5. The concentration of the triphosphate is determined using the extinction coefficient at $268 \mathrm{~nm}\left(5800 \mathrm{M}^{-1} \mathrm{~cm}^{-1}\right)$ for the nucleoside. ${ }^{31}$

${ }^{31} \mathrm{P}-\mathrm{NMR}(\mathrm{ppm}) \quad\left(\mathrm{D}_{2} \mathrm{O} /\right.$ Tris/EDTA) $\gamma-\mathrm{P}-5.72$, (d); $\alpha-\mathrm{P}$ $-10.29,(\mathrm{~d}) ; \beta-\mathrm{P}-21.44,(\mathrm{t})$.

${ }^{1} \mathrm{H}-\mathrm{NMR}(\mathrm{ppm})\left(\mathrm{D}_{2} \mathrm{O}\right) 2.45(\mathrm{~m}, 1 \mathrm{H}), 2.80(\mathrm{~m}, 1 \mathrm{H}), 4.10(\mathrm{~m}$, $2 \mathrm{H}), 4.18(\mathrm{~m}, 1 \mathrm{H}), 4.35(\mathrm{~m}, 1 \mathrm{H}), 6.59(\mathrm{~m}, 1 \mathrm{H}), 6.65(\mathrm{~m}, 1 \mathrm{H})$, $7.12(\mathrm{~m}, 1 \mathrm{H}), 7.25(\mathrm{~m}, 1 \mathrm{H}), 7.54-7.70(\mathrm{~m}, 3 \mathrm{H})$.

HiRes ESI-MS (-): Calculated mass spec (formula $\mathrm{C}_{13} \mathrm{H}_{17} \mathrm{~N}_{14} \mathrm{O}_{12} \mathrm{P}_{3}$ for $\mathrm{M}-\mathrm{H}$ ): 471.9964; Experimental mass spec: 471.9951

\section{1-(2-Deoxy-D-erythro-pentapyranosyl)- $1 H$-indole}

Pyranosides as side products were isolated from the synthesis of indole triphosphate using a procedure described by Smith et al $^{32}$ starting from indole nucleoside without addition of proton sponge. $\beta$ - and $\alpha$-isomer were eluted out of HPLC with $80 \% \mathrm{~B}$ and $100 \% \mathrm{~B}$, respectively.

\section{B-Isomer (3b)}

${ }^{1} \mathrm{H}-\mathrm{NMR}(\mathrm{ppm})$ (DMSO-d $\left.{ }_{6}\right) 1.83$ (m, 1H), 2.47 (m, 1H), 3.64 $3.73(\mathrm{~m}, 2 \mathrm{H}), 3.81-3.87(\mathrm{~m}, 2 \mathrm{H}), 4.67(\mathrm{~s}, 1 \mathrm{H}), 4.87(\mathrm{~s}, 1 \mathrm{H}), 5.63$ $(\mathrm{dd}, J=1.6,11,1 \mathrm{H}), 6.46(\mathrm{~d}, J=3,1 \mathrm{H}), 7.04(\mathrm{t}, J=7.5,1 \mathrm{H})$, $7.13(\mathrm{t}, J=7.5,1 \mathrm{H}), 7.46-7.59(\mathrm{~m}, 3 \mathrm{H})$.

${ }^{13}$ C-NMR (ppm) (DMSO-d ${ }_{6}$ ) 33.40, 66.70, 67.93, 68.91, $81.32,101.83,110.86,119.80,120.49,121.36,125.47,128.53$, 135.64 .

$$
\text { MS (FAB) M+1: } 234 \text {. }
$$

\section{a-Isomer (3a)}

${ }^{1} \mathrm{H}-\mathrm{NMR}$ (ppm) (DMSO-d $\left.{ }_{6}\right) 2.04$ (m, 1H), 2.47 (m, 1H), 3.57$3.62(\mathrm{~m}, 1 \mathrm{H}), 3.68-3.70(\mathrm{~m}, 1 \mathrm{H}), 3.80$ (t, $J=10,1 \mathrm{H}), 4.09$ (m, $1 \mathrm{H}), 4.83(\mathrm{~s}, 1 \mathrm{H}), 4.92(\mathrm{~s}, 1 \mathrm{H}), 5.86(\mathrm{dd}, J=1.2,10.1,1 \mathrm{H})$, $6.46(\mathrm{~d}, J=3,1 \mathrm{H}), 7.04(\mathrm{t}, J=7.5,1 \mathrm{H}), 7.14(\mathrm{t}, J=7.5,1 \mathrm{H})$, 7.47-7.55 (m, 3H).

${ }^{13} \mathrm{C}-\mathrm{NMR}$ (ppm) (DMSO-d $)_{6}$ 36.22, 65.39, 66.40, 66.56, $78.05,101.89,110.45,119.81,120.43,121.46,125.33,128.59$, 135.90 .

$$
\text { MS (FAB) M+1: } 234 .
$$

\section{Nucleotide insertion analyses}

Materials. $\left[\gamma_{-}{ }^{32} \mathrm{P}\right] \mathrm{ATP}$ was purchased from New England Nuclear. Unlabelled dNTPs (ultrapure) were obtained from Pharmacia. $\mathrm{MgCl}_{2}$ and Trizma base were from Sigma. Urea, acrylamide, and bis-acrylamide were from Aldrich. Oligonucleotides, including those containing a tetrahydrofuran moiety mimicking an abasic site, were synthesized by Operon Technologies (Alameda, CA). In all experiments, the 5 '-ends of the primer and template strands were labeled using $\left[\gamma-{ }^{32} \mathrm{P}\right] \mathrm{ATP}$ and T4 polynucleotide kinase (GibcoBRL). Thus, the labeled 20 -mer band present during autoradiographic analyses is provided as a loading control. Single-stranded and duplex DNA were purified and quantified as described. ${ }^{60}$ 5-NITP was obtained from TriLink BioTechnologies (San Diego, CA) in greater than $99 \%$ purity as well as synthesized as described below. All other materials were obtained from commercial sources and were of the highest available quality. The exonuclease-deficient mutant of gp43 (Asp-219 to Ala mutation) was purified and quantified as previously described. ${ }^{25,26}$

Methods. The assay buffer used in all kinetic studies consisted of $25 \mathrm{mM}$ Tris-OAc (pH 7.5), $150 \mathrm{mM} \mathrm{KOAc}$, and $10 \mathrm{mM}$ 2-mercaptoethanol. All assays were performed at $25^{\circ} \mathrm{C}$. Polymerization reactions were monitored by analysis of the products on $20 \%$ sequencing gels as described by Mizrahi et $a l^{61}$ Gel images were obtained with a Packard PhosphorImager using the OptiQuant software supplied by the manufacturer. Product formation was quantified by measuring the ratio of ${ }^{32} \mathrm{P}$-labelled extended and non-extended primer. 
The ratios of product formation are corrected for substrate in the absence of polymerase (zero point). Corrected ratios are then multiplied by the concentration of primer/template used in each assay to yield total product. All concentrations are listed as final solution concentrations.

The kinetic parameters, $k_{\text {cat }}, K_{\mathrm{m}}$, and $k_{\text {cat }} / K_{\mathrm{m}}$, for each dNTP during DNA synthesis were obtained by monitoring the rate of product formation using a fixed amount of gp43 $(50 \mathrm{nM})$ and DNA substrate $(1000 \mathrm{nM})$ at varying concentrations of nucleotide triphosphate $(0.01-1 \mathrm{mM})$. Aliquots of the reaction were quenched into $0.5 \mathrm{M}$ ethylenediaminetetraacetate (EDTA), $\mathrm{pH}$ 7.4 at times ranging from 5-600 seconds. Samples were diluted 1 : 1 with sequencing gel load buffer and products were analyzed for product formation by denaturing gel electrophoresis. In all cases, steady-state rates were obtained from the linear portion of the time course. Data obtained for steadystate rates in DNA polymerization measured under pseudo-first order reaction conditions were fit to equation 1

$$
y=m t+b
$$

where $m$ is the slope of the line, $b$ is the $y$-intercept, and $t$ is time. The slope of the line is equivalent to the rate of the reaction, $v$, and is defined as $\mathrm{nM} \mathrm{s}{ }^{-1}$. Data for the dependency of $v$ as a function of dNTP concentration were fit to the MichaelisMenten equation

$$
v=V_{\text {max }}[\mathrm{dNTP}] / K_{\mathrm{m}}+[\mathrm{dNTP}]
$$

where $v$ is the rate of the reaction, $V_{\max }$ is the maximal rate of the reaction, $K_{\mathrm{m}}$ is the Michaelis constant for dNTP, and dNTP is the concentration of nucleotide substrate. $k_{\text {cat }}$ is defined as $V_{\max } /[\mathrm{gp} 43]$

To measure the rates of elongation beyond Ind-MP, experiments were performed under single turnover conditions. In these experiments, gp43 $(1 \mu \mathrm{M})$ was incubated with $500 \mathrm{nM} \mathrm{13/}$ $20 \mathrm{X}$-mer ( $\mathrm{X}$ is any natural nucleobase or an abasic site) in assay buffer containing $10 \mathrm{mM} \mathrm{Mg}$ acetate and mixed with $150 \mu \mathrm{M}$ indole-TP for 5 minutes prior to the addition of $500 \mu \mathrm{M} \mathrm{dGTP}$ the correct nucleotide for the next three insertion positions. The reactions were quenched with $200 \mathrm{mM}$ EDTA at variable times (5-180 s) and analyzed as described above.

\section{Acknowledgements}

This research was supported through funding from the American Cancer Society Cuyahoga Unit to AJB (021203A) and from the Presidential Research Initiative to IL.

\section{References}

1 A. Kornberg and T. A. Baker, in DNA Replication, 2nd edn., W. H. Freeman and Company, New York, 1992, pp. 1-25.

2 K. Skarstad and S. Wold, Mol. Microbiol., 1995, 17, 825-831.

3 M. F. Goodman, S. Creighton, L. B. Bloom and J. Petruska, Crit. Rev. Biochem. Mol. Biol., 1993, 28, 83-126.

4 B. T. Eger and S. J. Benkovic, Biochemistry, 1992, 31, 9227-9236.

5 W. A. Beard, D. D. Shock, B. J. Vande Berg and S. H. Wilson, J. Biol. Chem., 2002, 277, 47393-47398.

6 A. M. Shah, M. Maitra and J. B. Sweasy, Biochemistry, 2003, 42 10709-10717.

7 H. B. Tan, P. F. Swann and E. M. Chance, Biochemistry, 1993, 33, 5335-5346.

8 I. Wong, S. S. Patel and K. A. Johnson, Biochemistry, 1991, 30 526-537

9 A. K. Showalter and M. D. Tsai, Biochemistry, 2002, 41, 10571-10576.

10 G. E. Plum and K. J. Breslauer, Ann. N. Y. Acad. Sci., 1994, 726, 45-55.

11 K. A. Johnson, Annu. Rev. Biochem., 1993, 62, 685-713.

12 E. T. Kool, Annu. Rev. Biophys. Biomol. Struct., 2001, 30, 1-22.

13 M. F. Goodman, Proc. Natl. Acad. Sci. USA, 1997, 94, 10493-10495.

14 S. Moran, R. X. Ren and E. T. Kool, Proc. Natl. Acad. Sci. USA, 1997, 94, 10506-10511.

15 T. J. Matray and E. T. Kool, Nature, 1999, 399, 704-708.
16 J. C. Morales and E. T. Kool, J. Am. Chem. Soc., 2000, 122, 1001-1007.

17 J. Horlacher, M. Hottiger, V. N. Podust, U. Hubscher and S. A. Benner, Proc. Natl. Acad. Sci. USA, 1995, 92, 6329-6333.

18 G. C. Hoops, P. Zhang, W. T. Johnson, N. Paul, D. E. Bergstrom and V. J. Davisson, Nucleic Acids Res., 1997, 25, 4866-4871.

19 D. E. Bergstrom, P. Zhang and W. T. Johnson, Nucleic Acids Res., 1997, 25, 1935-1942.

20 D. A. Harki, J. D. Graci, V. S. Korneeva, S. K. Ghosh, Z. Hong, C. E. Cameron and B. R. Peterson, Biochemistry, 2002, 41, 9026-9033.

21 S. Matsuda, A. A. Henry, P. G. Schultz and F. E. Romesberg, J. Am. Chem. Soc., 2003, 125, 6134-6139.

22 I. Hirao, M. Kimoto, S. Yamakage, M. Ishikawa, J. Kikuchi and S. Yokoyama, Bioorg. Med. Chem. Lett., 2002, 12, 1391-1393.

23 E. T. Kool, Annu. Rev. Biochem., 2002, 71, 191-219.

24 E. Z. Reineks and A. J. Berdis, Biochemistry, 2004, 43, 393-404.

25 T. L. Capson, J. A. Peliska, B. F. Kaboord, M. W. Frey, C. Lively, M. Dahlberg and S. J. Benkovic, Biochemistry, 1992, 31, 10984-10994.

26 M. W. Frey, N. G. Nossal, T. L. Capson and S. J. Benkovic, Proc. Natl. Acad. Sci. USA, 1993, 90, 2579-2583.

27 A. J. Berdis, Biochemistry, 2001, 40, 7180-7191.

28 J. Wang, A. K. M. A. Sattar, C. C. Wang, J. D. Karam, W. H. Konigsberg and T. A. Steitz, Cell, 1997, 89, 1087-1099.

29 Y. Shamoo and T. A. Steitz, Cell, 1999, 99, 155-166.

30 M. C. Franklin, J. Wang and T. A. Steitz, Cell, 2001, 105, 657-667.

31 N. S. Girgis, H. B. Cottam and R. K. Robins, J. Heterocycl. Chem., 1998, 25, 361-365.

32 C. L. Smith, A. C. Simmonds, I. R. Felix, A. L. Hamilton, S. Kumar, S. Nampali, D. Loakes and D. M. Brown, Nucleosides Nucleotides, 1998, 17, 541-554.

33 M. Hoffer, Chem. Ber., 1960, 93, 2777-2781.

34 F. Seela, S. Menkhoff and S. Behrendt, J. Chem. Soc., Perkin Trans. 2, 1986, 525.

35 H.-D. Winkeler and F. Seela, Liebigs Ann. Chem., 1984, 708.

36 T. Kovács and L. Ötvös, Tetrahedron Lett., 1988, 29, 4525.

37 K. M. Guckian, B. A. Scheitzer, R. X.-F. Ren, C. J. Sheils, P. L. Paris, D. C. Tahmassebi and E. T. Kool, J. Am. Chem. Soc., 1996, 118, 8182-8183.

38 L. B. Bloom, M. R. Otto, J. M. Beechem and M. F. Goodman, Biochemistry, 1993, 32, 11247-11258.

39 H. T. Allawi and J. SantaLucia, Jr., Biochemistry, 1998, 37, 9435 9444.

40 I. Rouzina and V. A. Bloomfield, Biophys. J., 1999, 77, 3252-3255.

41 D. Loakes, Nucleic Acids Res., 2001, 29, 2437-2447.

42 H. Cai, L. B. Bloom, R. Eritja and M. F. Goodman, J. Biol. Chem., 1993, 268, 23567-23572.

43 E. Efrati, G. Tocco, R. Eritja, S. H. Wilson and M. F. Goodman, J. Biol. Chem., 1997, 272, 2559-2569.

44 D. J. Mozzherin, S. Shibutani, C. K. Tan, K. M. Downey and P. A. Fisher, Proc Natl. Acad Sci. USA, 1997, 94, 6126-6131.

45 M. G. Greenberg and T. J. Matray, Biochemistry, 1997, 36, 14071-14079.

46 T. E. Spratt, Biochemistry, 2001, 40, 2647-2652.

47 S. Matsuda, A. A. Henry, P. G. Schultz and F. E. Romesberg, J. Am. Chem. Soc., 2003, 125, 6134-6139.

48 M. T. Washington, W. T. Wolfle, T. E. Spratt, L. Prakash and S. Prakash, Proc. Natl. Acad. Sci. USA, 2003, 100, 5113-5118.

49 I. Hirao, T. Ohtusuki, T. Mitsui and S. Yokoyama, J. Am. Chem. Soc., 2000, 122, 6118-6119.

50 E. L. Tae, Y. Wu., G. Xia, P. G. Schultz and F. E. Romesberg, J. Am. Chem. Soc., 2001, 123, 7439-7440.

51 C. A. Brautigam and T. A. Steitz, Curr. Opin. Struct. Biol., 1998, 8, 54-63.

52 S. J. Benkovic and C. E. Cameron, Methods Enzymol., 1995, 262, 257-269.

53 E. Arnold, J. Ding, S. H. Hughes and Z. Hostomsky, Curr. Opin. Struct. Biol., 1995, 5, 27-38.

54 T. A. Steitz, J. Biol. Chem., 1999, 274, 17395-17398.

55 M. C. Franklin, J. Wang and T. A. Steitz, Cell, 2001, 105, $657-667$.

56 Y. Li, S. Korolev and G. Waksman, EMBO J., 1998, 17, 7514-7525.

57 D. K. Braithewaite and J. Ito, Nucleic Acids Res., 1993, 21, 787-802.

58 C.-C. Wang, L. S. Yeh and J. Karam, J. Biol. Chem., 1995, 270, 26558-26564.

59 G. E. Wright and N. C. Brown, Pharmacol. Ther., 1990, 47, 447-497.

60 R. D. Kuchta, P. Benkovic and S. J. Benkovic, Biochemistry, 1988, 27, 6716-6725.

61 V. Mizrahi, P. A. Benkovic and S. J. Benkovic, Proc. Natl. Acad. Sci. $U S A, 1986,83,231-235$. 